\title{
UHV-STM Investigations and Numerical Calculations of a Ruthenium $\beta$-Diketonato Complex with Protected Ethynyl Ligand: [Ru(dbm) $\left.)_{2}(\mathbf{a c a c}-\mathrm{TIPSA})\right]$
}

\author{
Loranne Vernisse ${ }^{1,2}$, Sabrina Munery ${ }^{1,3}$, Nicolas Ratel-Ramond ${ }^{1}$, Youness Benjalal ${ }^{1}$, Olivier \\ Guillermet $^{1,2}$, Xavier Bouju ${ }^{1}$, Roland Coratger ${ }^{1,2}$, and Jacques Bonvoisin ${ }^{1,3, *}$. \\ 1 CEMES, CNRS UPR 8011, Nanosciences Group, 29 rue Jeanne Marvig, BP 94347, 31055 Toulouse, France \\ 2 CEMES, Université de Toulouse, 29 rue Jeanne Marvig, BP 94347, 31055 Toulouse, France \\ 3 CEMES, MANA Satellite, 29 rue Jeanne Marvig, BP 94347, 31055 Toulouse, France
}

KEYWORDS: Ruthenium, $\beta$-diketonato, Adsorption, Scanning Tunneling Microscopy, Ultra High Vacuum, Low Temperature, Image Calculations.

\begin{abstract}
The quest of molecular electronic devices necessitates addressing model molecular systems as starting points. Among the targeted functions, electron transfer between specific moieties inside a molecule is expected to play a fundamental role for ultimate logical gates. Here we propose a coordination complex exhibiting two inorganic centers (Ru and $\mathrm{Si}$ ) that constitutes a step towards a more complex architecture. Starting from the complex $1\left[\mathrm{Ru}(\mathrm{dbm})_{2}(\mathrm{acac}-\mathrm{I})\right](\mathrm{dbm}=$ dibenzoylmethanate ion, acac-I $=3$-iodo-2,4-pentanedionate ion), the complex 2 [Ru(dbm) ${ }_{2}$ (acac-TIPSA)] (acac-TIPSA=3-(triisopropylsilyl)acetylene-2,4pentanedionate ion) was obtained through Sonogashira cross coupling reaction under classical conditions. This complex 2 was characterized by elemental analysis, IR, ${ }^{1} \mathrm{H}$ NMR, ${ }^{13} \mathrm{C}$ NMR, UV-Vis, cyclic voltammetry, mass spectroscopy as well as X-ray single crystal diffraction. It crystallized with empirical formula of $\mathrm{C}_{46} \mathrm{H}_{49} \mathrm{O}_{6} \mathrm{Ru}_{1} \mathrm{Si}_{1}$ in a monoclinic crystal system and space group $\mathrm{P} 2{ }_{1} / \mathrm{c}$ with $a=21.077(3) \AA, b=9.5130(7) \AA, \mathrm{c}=21.8790(12) \AA, \beta=94.125(7)^{\circ}, V=4375.5(7) \AA^{3}$ and $Z=4$. Additionally, scanning tunneling microscopy measurements at liquid He temperature and in an ultra-high vacuum (UHV-STM) were conducted on complex 2 on a $\operatorname{Ag}(111)$ surface. The STM images, supported by adsorption and STM image calculations, demonstrate that the molecules exist in two stable forms when adsorbed on the metallic surface.
\end{abstract}

\section{INTRODUCTION}

Single molecule electronic components are investigated as the building blocks for next generation electronic devices. ${ }^{1}$ In particular, metal complexes, particularly simple magnetic molecules, may be seen as such fundamental elements to construct efficient logic gates. ${ }^{2-6}$ Therefore deposition and adsorption of such systems onto a substrate and the investigation of their behavior and properties are of primary importance in the perspective of potential applications. Among the large variety of molecular systems already targeted, a specific class is relevant for spintronics ${ }^{7}$ or data storage applications. In particular, an effort to design molecules with magnetic properties has to be developed and their characterization as building blocks for such type of electronics has to be tackled at the single molecule level.

Scanning tunneling microscopy (STM) has been proven to be a powerful tool to study various surfaces at the atomic and molecular level. ${ }^{8}$ Moreover, scanning tunneling spectroscopy and/or spin-polarized STM ${ }^{9,10}$ provide valuable information on magnetic properties of atomic, ${ }^{11-13}$ molecular, ${ }^{14,15}$ and nano-islands ${ }^{16-18}$ systems. Other specific properties have been also addressed like Kondo effect on atomic centres ${ }^{19-23}$ or with single molecules ${ }^{24-26}$, as well as Kondo lattices and RKKY coupling ${ }^{27-29}$ or splinflipping. ${ }^{30-32}$

Although STM is able to give atomic resolution when imaging solid surfaces, mapping of large and complex molecules with submolecular resolution remains a difficult task, since in particular the molecular deformation due to surface interaction plays a crucial role. ${ }^{33-35}$

Among molecules with magnetic centres, ruthenium complexes may be of particular interest to study charge transfer or transport phenomena at the nanometer scale. ${ }^{36-42}$ In a previous paper, we reported the investigation of a series of ruthenium tris $(\beta$ diketonato)complexes by UHV-STM. ${ }^{43}$ Here, the synthesis and characterization of a new ruthenium $\beta$-diketonato complex with 
protected ethynyl ligand $\left[\mathrm{Ru}(\mathrm{dbm})_{2}(\right.$ acac-TIPSA) 2 is reported. Single molecules adsorbed on the $\mathrm{Ag}(111)$ surface have been also investigated by STM in ultra-high vacuum (UHV) environment at low temperature coupled to molecular adsorption calculations and STM image calculations. Our results demonstrate the complex $\mathbf{2}$ adopts two different stable conformations on the surface without modification of the coordination sphere around the ruthenium atom.

\section{EXPERIMENTAL METHODS}

2.1. Materials. All chemicals and solvents were of reagent grade or better. The complexes were purified by column chromatography using Silica gel 60 (Merck or Agela). Elemental analyses were performed by the "Service de microanalyse ICSNCNRS Gif/Yvette".

2.2. Physical Measurements. UV-Visible spectra were recorded on a Varian Cary 5000 spectrophotometer. Cyclic voltammograms were obtained with an Autolab system (PGSTAT100) in $\mathrm{CH}_{2} \mathrm{Cl}_{2}$ (DCM) (0.1 M tetrabutylammonium hexafluorophosphate, TBAH as supporting electrolyte) at $25^{\circ} \mathrm{C}$. A three-electrode cell was used comprising a $1 \mathrm{~mm}$ Pt-disk working electrode, a Pt wire auxiliary electrode, and an aqueous saturated calomel (SCE) reference electrode. Mass spectra were recorded by the 'Service de Spectroscopie de Masse' of Paul Sabatier University using FAB (Nermag R10-R10, NBA matrix) in positive mode. ${ }^{1} \mathrm{H}$ NMR and ${ }^{13} \mathrm{C}$-NMR spectra were taken on Bruker Avance $500 \mathrm{MHz}$ equipment in $\mathrm{CD}_{2} \mathrm{Cl}_{2}$.

2.3. STM Studies. STM experiments were performed in an Omicron low-temperature ultra-high vacuum STM with a base pressure of $1.5 .10^{-11}$ mbar. The Ag(111) single crystal was cleaned by repeated $\mathrm{Ar}^{+}$sputtering and annealing at $810 \mathrm{~K}$. Molecules were first deposited on a $0.15 \mathrm{~mm}$ diameter tungsten filament submitted to high temperature outgassing cycles before evaporations. These molecules were then evaporated at about $250^{\circ} \mathrm{C}$ directly on the STM head, i.e. while the substrate was held at liquid helium temperature. In this case, the vacuum never exceeds $1.4 .10^{-10}$ mbar in the STM chamber. The tunneling measurements were carried out at $4.5 \mathrm{~K}$. Tips were made of $250 \mu \mathrm{m}$ diameter tungsten wires and prepared by electrochemical etching in a $1 \mathrm{M}-\mathrm{NaOH}$ solution. They were cleaned in the UHV preparation chamber using direct current heating. Bias voltages V refer to the sample voltage with respect to the tip. All STM images presented in this paper were acquired in constant current mode and are given without any data processing.

2.4. X-ray diffraction studies. A suitable crystal was first selected under a binocular and then mounted onto a goniometer head using cyanolite. The diffraction data were collected using an Enraf Kappa-CCD automatic XRay single crystal diffractometer, using MoK $\alpha$ radiation, for which a graphite monochromator was used. Intensities were measured using an Apex 2 detector at sample to detector distance of $50 \mathrm{~mm}$ and at a temperature of $190 \mathrm{~K}$. This temperature was achieved by injecting an air flow that was cooled using liquid nitrogen. The crystallographic cell was found using EVAL-CCD. ${ }^{44}$ The point group determination was followed by the determination of the position of all non hydrogen atoms by direct methods using SIR2004 ${ }^{45}$ and refined in the WinGX software package ${ }^{46}$ using SHELX-97. ${ }^{47}$ Absorption corrections were performed using the SADABS program. ${ }^{48,}{ }^{49}$ The refined cell constants and additional crystal data are given in Table S1 (See Supplementary materials). The non hydrogen atoms were easily localized after structure determination and subsequent Fourier analyses have revealed the position of the hydrogen atoms. The latter were introduced as riding with their relevant parent atoms. The refinements were performed using anisotropic thermal displacement parameters for all the non-hydrogen atoms.

CCDC-833276 (for 2) contains the supplementary crystallographic data for this paper. These data can be obtained free of charge from the Cambridge Crystallographic Data Centre via www.ccdc.cam.uk/data_request/cif

2.5. Synthesis of the complex $\left[\mathbf{R u}(\mathbf{d b m})_{2}(\mathbf{a c a c}-T I P S A)\right] 2$ : The reaction was operated under vacuum line. $0.24 \mathrm{~g}(0.32 \mathrm{mmol})$ of $\left[\mathrm{Ru}(\mathrm{dbm})_{2}(\mathrm{acac}-\mathrm{I})\right] \mathbf{1}$ were introduced in a schlenk. Were added successively $8 \mathrm{~mL}$ of distilled $\left.\mathrm{THF}, \mathrm{Pd}_{(\mathrm{PPh}}\right)_{4}(0.04 \mathrm{~g}, 0.04$ $\mathrm{mmol})$, CuI (0.008 g, $0.04 \mathrm{mmol}), 2 \mathrm{~mL}$ of redistilled Diisopropylamine (DIPA) and $0.353 \mathrm{~mL}$ (1.57 mmol) of (triisopropylsilyl)acetylene (TIPSA). Between each addition, three vacuum-argon cycles were performed. TLC was used to check the reaction on silica with toluene. After 23 hours of stirring at room temperature, the reaction was stopped. During the reaction no real colour change was observed. After evaporation of solvents, the crude product was purified by column chromatography on silica with a mixture of toluene/cyclohexane (50:50). After evaporation to dryness, black crystals $\left[\mathrm{Ru}(\mathrm{dbm})_{2}\right.$ (acac-TIPSA)] were obtained with a yield of $30 \%$. Anal. Calc. (\%) for $\mathrm{C}_{46} \mathrm{H}_{49} \mathrm{O}_{6} \mathrm{RuSi}$ : C, 66.8; H, 6.0. Found: C, 66.6; H, 6.0. Mass spectroscopy (FAB, DCM, MNBA) m/z: $827 \mathrm{M}^{+}$(calc. 827.03), 647 [M-TIPSA] ${ }^{+}, 548$ [M-Acac-TIPSA] ${ }^{+}$IR (KBr) v/cm ${ }^{-1} 1521(\mathrm{C}=\mathrm{O}), 1563$ and $1484(\mathrm{C}=\mathrm{C})$, $2140(\mathrm{C} \equiv \mathrm{C})$ and 2924 and $2863(\mathrm{CH} \mathrm{sp} 3) . \mathrm{CV}\left(\mathrm{DCM}, 0.1 \mathrm{M} \mathrm{TBAH}, 0.1 \mathrm{~V} \cdot \mathrm{s}^{-1}\right.$, vs.SCE) $\mathrm{E}_{1 / 2}\left(\mathrm{Ru}^{\mathrm{III}} / \mathrm{Ru}^{\mathrm{II}}\right)=-0.618 \mathrm{~V},|\Delta \mathrm{E}|=0.078 \mathrm{~V}$, $\mathrm{E}_{1 / 2}\left(\mathrm{Ru}^{\mathrm{III}} / \mathrm{Ru}^{\mathrm{IV}}\right)=1.033 \mathrm{~V},|\Delta \mathrm{E}|=0.078 \mathrm{~V}$. UV-Vis. Spectroscopy $\left(\mathrm{DCM}, 9.7 \times 10^{-5} \mathrm{M}\right) \lambda / \mathrm{nm}\left(\varepsilon / 10^{3} \mathrm{M}^{-1} . \mathrm{cm}^{-1}\right) 570(1.9), 413(9.1)$, 330 (33.2), 258 (33.0). ${ }^{1} \mathrm{H}$ NMR $\left(\mathrm{CD}_{2} \mathrm{Cl}_{2}, \delta=5.32 \mathrm{ppm}\right) 12.70\left(4 \mathrm{H}, \mathrm{s}, \mathrm{H}_{\mathrm{i}}\right), 12.62\left(4 \mathrm{H}, \mathrm{s}, \mathrm{H}_{\mathrm{c}}\right), 9.96(2 \mathrm{H}, \mathrm{t}, \mathrm{J}=6.5 \mathrm{~Hz}, \mathrm{H}), 9.89(2 \mathrm{H}$, $\left.\mathrm{t}, \mathrm{J}=6.5 \mathrm{~Hz}, \mathrm{H}_{\mathrm{k}}\right), 6.64\left(4 \mathrm{H}, \mathrm{d}, \mathrm{J}=6.7 \mathrm{~Hz}, \mathrm{H}_{\mathrm{j}}\right), 6.45\left(4 \mathrm{H}, \mathrm{d}, \mathrm{J}=6.7 \mathrm{~Hz}, \mathrm{H}_{\mathrm{b}}\right), 1.94\left(6 \mathrm{H}, \mathrm{s}, \mathrm{H}_{\mathrm{l}}\right), 1.46\left(21 \mathrm{H}, \mathrm{m}, \mathrm{H}_{\mathrm{r}}\right.$ and $\left.\mathrm{H}_{\mathrm{q}}\right),-42.80(2 \mathrm{H}$, $\left.\mathrm{s}, \mathrm{H}_{\mathrm{f}}\right) .{ }^{13} \mathrm{C} \mathrm{NMR}\left(\mathrm{CD}_{2} \mathrm{Cl}_{2}, \delta=53.7 \mathrm{ppm}\right) 139.02(\mathrm{~b}), 137.90(\mathrm{j}), 122.85(\mathrm{k}), 121.50(\mathrm{a}), 116.20(\mathrm{~d}), 108.86(\mathrm{i}), 106.08(\mathrm{c}), 105.11$ (h), 26.17 (q), 19.54 (r), -14.71 (l).

\section{RESULTS AND DISCUSSION}

3.1. Synthesis and chemical characterization. The synthesis of complex 2 follows the procedure given in 
Scheme 1. Complex 2 was prepared by a Sonogashira cross coupling reaction between the already described iodoruthenium complex $\mathbf{1}^{43}$ and triisopropylsilylacetylene (TIPSA) under classical condition (CuI, $\left.\mathrm{Pd}\left(\mathrm{PPh}_{3}\right)_{4}, \mathrm{THF} / \mathrm{DIPA}\right)$ with a reasonable yield $(30 \%)$ compared to other similar compounds. ${ }^{50}$

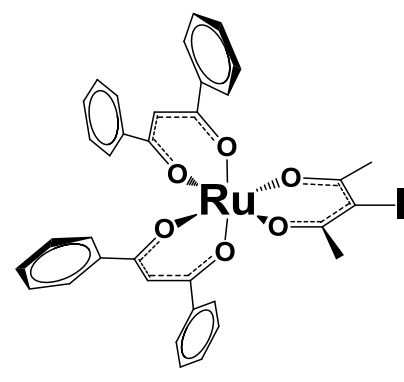

1

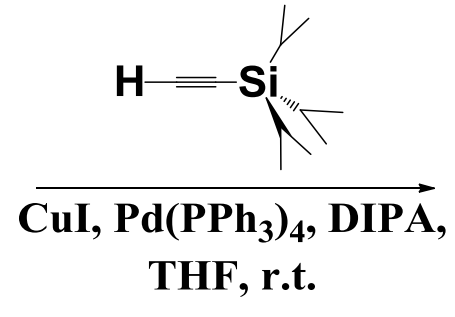

THF, r.t.

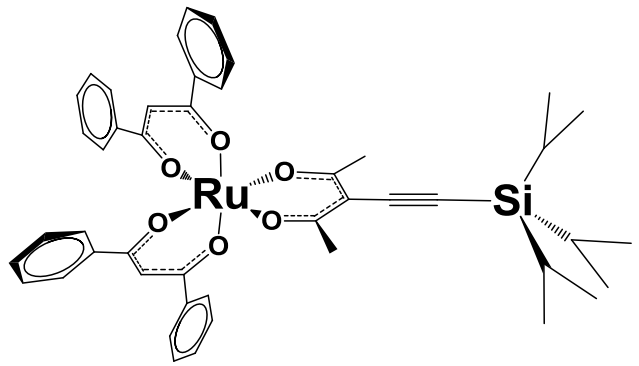

2

$30 \%$

\section{Scheme 1.}

Cyclic voltammetry $(\mathrm{CV})$ data for complex 2 are given in the experimental section and also in Figure $\mathrm{S} 1$. The $\mathrm{E}_{1 / 2}$ potentials were determined from the average of the anodic and cathodic peaks potentials. The reversible half-wave potentials $\mathrm{E}_{1 / 2}$ of 1 ( $-0.613 \mathrm{~V}$, $1.045 \mathrm{~V})^{43}$ and $2(-0.618 \mathrm{~V}, 1.033 \mathrm{~V})$ which correspond to the $\mathrm{Ru}^{\mathrm{III}} / \mathrm{Ru}^{\mathrm{II}}$ and $\mathrm{Ru}^{\mathrm{IV}} / \mathrm{Ru}^{\mathrm{III}}$ redox couples respectively are very similar. This has already been observed in other ruthenium compounds. ${ }^{51}$

The UV/Vis data are shown in Figure 1 and Figure S2. Complex 2 presents three strong bands $\left(258 \mathrm{~nm}\left(33000 \mathrm{M}^{-1} \mathrm{~cm}^{-1}\right) ; 330 \mathrm{~nm}\right.$ $\left.\left(33200 \mathrm{M}^{-1} \mathrm{~cm}^{-1}\right) ; 413 \mathrm{~nm}\left(9100 \mathrm{M}^{-1} \mathrm{~cm}^{-1}\right)\right)$ and one weaker band $\left(570 \mathrm{~nm}\left(1890 \mathrm{M}^{-1} \mathrm{~cm}^{-1}\right)\right)$ in the UV/Vis area. This spectrum is very comparable to the ones observed for similar compounds. ${ }^{43}$ Reduction and oxidation of complex 2 by electrolysis at constant potential (-1V vs SCE for the reduction and $+1.25 \mathrm{~V}$ vs SCE for the oxidation) leads to the spectra shown in Figure 1. For the reduction process, two new bands appear at $554 \mathrm{~nm}\left(7210 \mathrm{M}^{-1} \mathrm{~cm}^{-1}\right)$ and $656 \mathrm{~nm}\left(7870 \mathrm{M}^{-1} \mathrm{~cm}^{-1}\right)$ which are probably MLCT type. For the oxidation, a broad band appears centered around $980 \mathrm{~nm}\left(4510 \mathrm{M}^{-1} \mathrm{~cm}^{-1}\right)$ and is probably LMCT type.

NMR experiments have been made on complex 2. All the NMR $\left({ }^{1} \mathrm{H}\right.$ and $\left.{ }^{13} \mathrm{C}\right)$ spectra are shown on supplementary materials $(c f$. supplementary materials, Figures S3 and S4). The ${ }^{1} \mathrm{H}$ and ${ }^{13} \mathrm{C}$ signals were assigned on the basis of chemical shifts, spin-spin coupling constants, splitting patterns, and signal intensities, by using ${ }^{1} \mathrm{H}-{ }^{1} \mathrm{H}$ COSY; and also by comparison with their homologues.

${ }^{43}$ They are presented in the experimental section. It has to be noted that the two carbons of the triple bond (noted o,p) and the other carbons close to them (noted $\mathrm{m}, \mathrm{n}$ ) and also e and $\mathrm{g}$ are not visible in the ${ }^{13} \mathrm{C}$ NMR and consequently not assigned. This is probably due to the proximity of the paramagnetic $\mathrm{Ru}^{\mathrm{III}}$ centre.

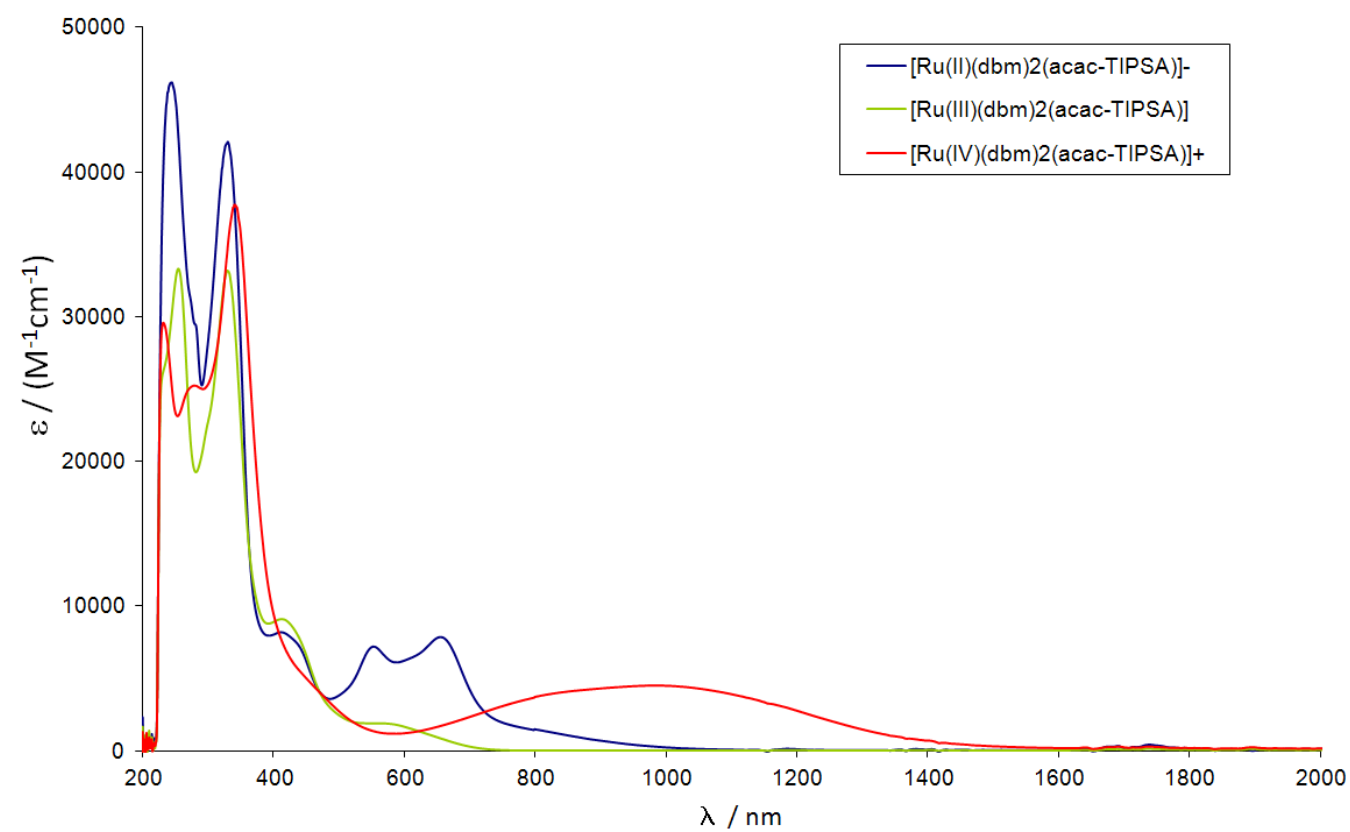

Figure 1. UV-Vis spectra of complex 2 in the neutral (green line), reduced (blue line) and oxidized (red line) forms in $\mathrm{CH} 2 \mathrm{Cl} 2 . \mathrm{Reduced}$ and oxidized species have been obtained by electrolysis at constant potential (-1V /SCE and $+1.25 \mathrm{~V} / \mathrm{SCE}$ respectively) in $\mathrm{CH} 2 \mathrm{Cl} 2$, TBAH $0.1 \mathrm{M}$. 
Crystal structure data for complex 2 are given in Table S1 (See supplementary materials). Selected bond lengths and angles are reported in Tables S2. Figure 2 shows the ORTEP drawing of 2. The ruthenium atom is in an octahedral environment surrounded by six oxygen atoms, four coming from $\mathrm{dbm}$ and two from acac ligands. The Ru-O distances and the bond angles are consistent with the range of values reported for the same kind of systems. ${ }^{43,52}$

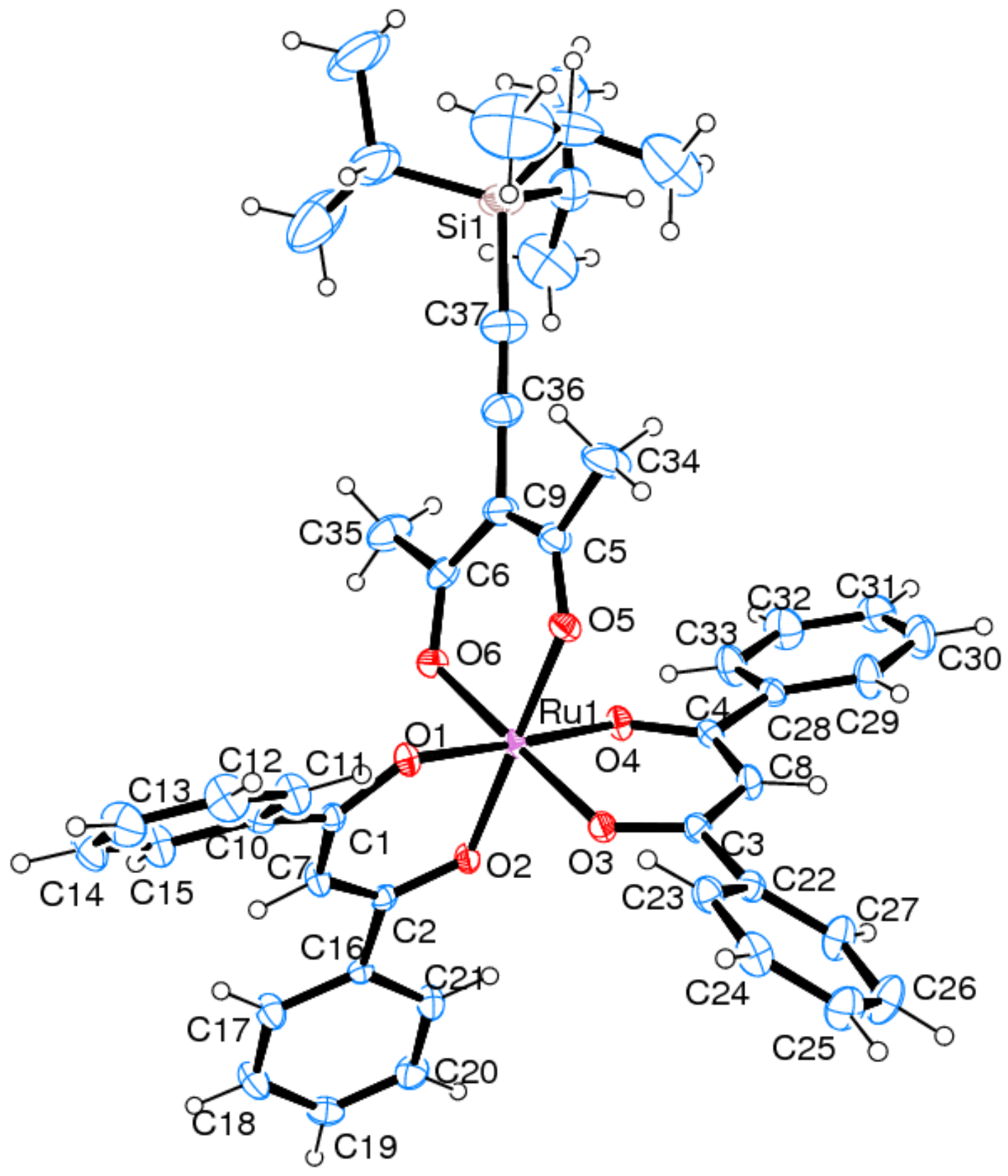

Figure 2. ORTEP drawing of $\left[\mathrm{Ru}(\mathrm{dbm})_{2}(\mathrm{acac}-\mathrm{TIPSA})\right] \mathbf{2}$ (30\% of probability thermal ellipsoids)

3.2. STM Experiments. In order to characterize precisely the conformation of the molecule on the Ag(111) surface, UHVSTM experiments were performed. After evaporation of complex 2 on $\operatorname{Ag}(111)$ held at liquid helium temperature, the surface is covered by two different objects always presenting the same shape. These two objects are labeled (I) and (II) and are shown in Figure 3. The lack of small fragments on the STM images can be noticed. This particularly shows that molecules are not destroyed during evaporation in spite of its large dimensions. It should also be noted that the general shape of these two forms does not drastically change when one changes the bias voltage in the $-2 \mathrm{~V}$ to $2 \mathrm{~V}$ range. 


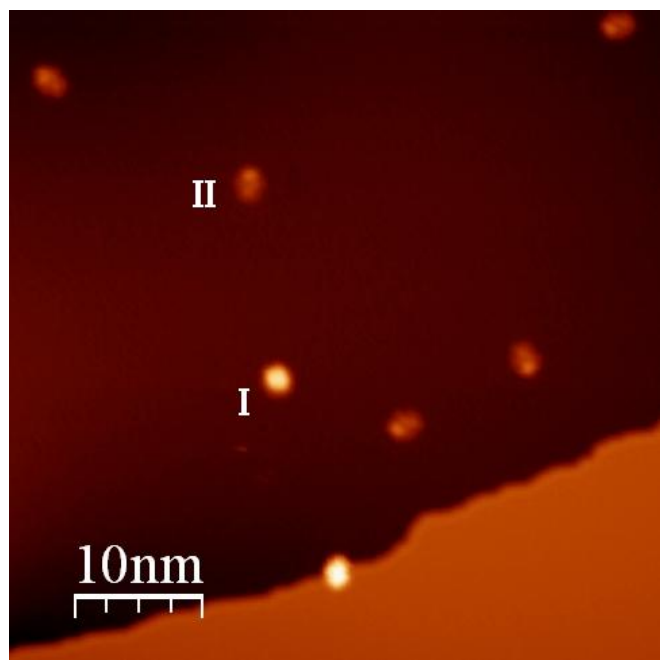

Figure 3. STM image $\left(50 \times 50 \mathrm{~nm}^{2}\right)$ of the $\operatorname{Ag}(111)$ surface after evaporation of $\left[\mathrm{Ru}(\mathrm{dbm})_{2}(\mathrm{acac}-\mathrm{TIPSA})\right]$ on a substrate held at liquid helium temperature (sample voltage $1.5 \mathrm{~V}$, tunneling current $2 \mathrm{pA}$ ). Two typical images of individual molecules are marked I and II.

Two objects of type (I) are shown in Figure 4. They are quite noisy and present a single circular structure. Their apparent diameter and height are about $2 \mathrm{~nm}$ and $6 \AA$ respectively (Figure $4 b$ ). This large corrugation involved very small displacements of the molecules while scanning which explains their noisy appearance. However, the conformation of this object never changes during the tip scanning, which reveals a high stability on the surface. Moreover, step edges, defects or number of molecules deposited on the surface do not influence the form of adsorbed molecules.
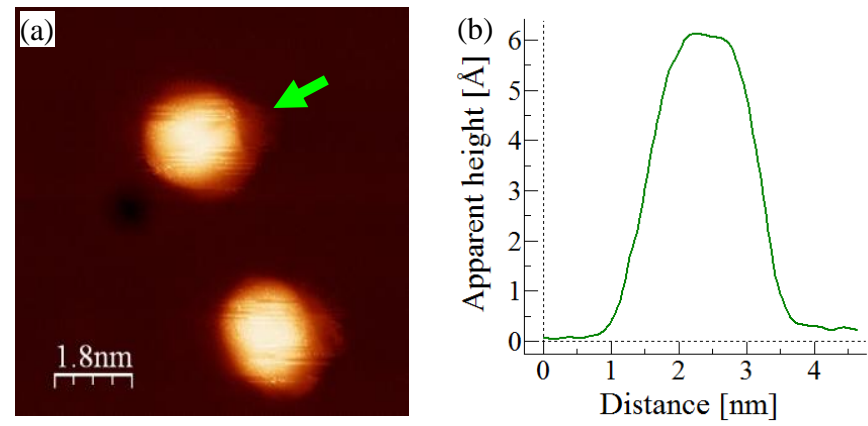

Figure 4. (a) STM image $\left(9 \times 9 \mathrm{~nm}^{2}\right)$ of two type (I) molecules (sample voltage $1 \mathrm{~V}$, tunneling current 2 pA). (b) Profile along the molecule (I) (direction indicated by the green arrow in (a)) showing an apparent height above the $\operatorname{Ag}(111)$ of about $6 \AA$. 

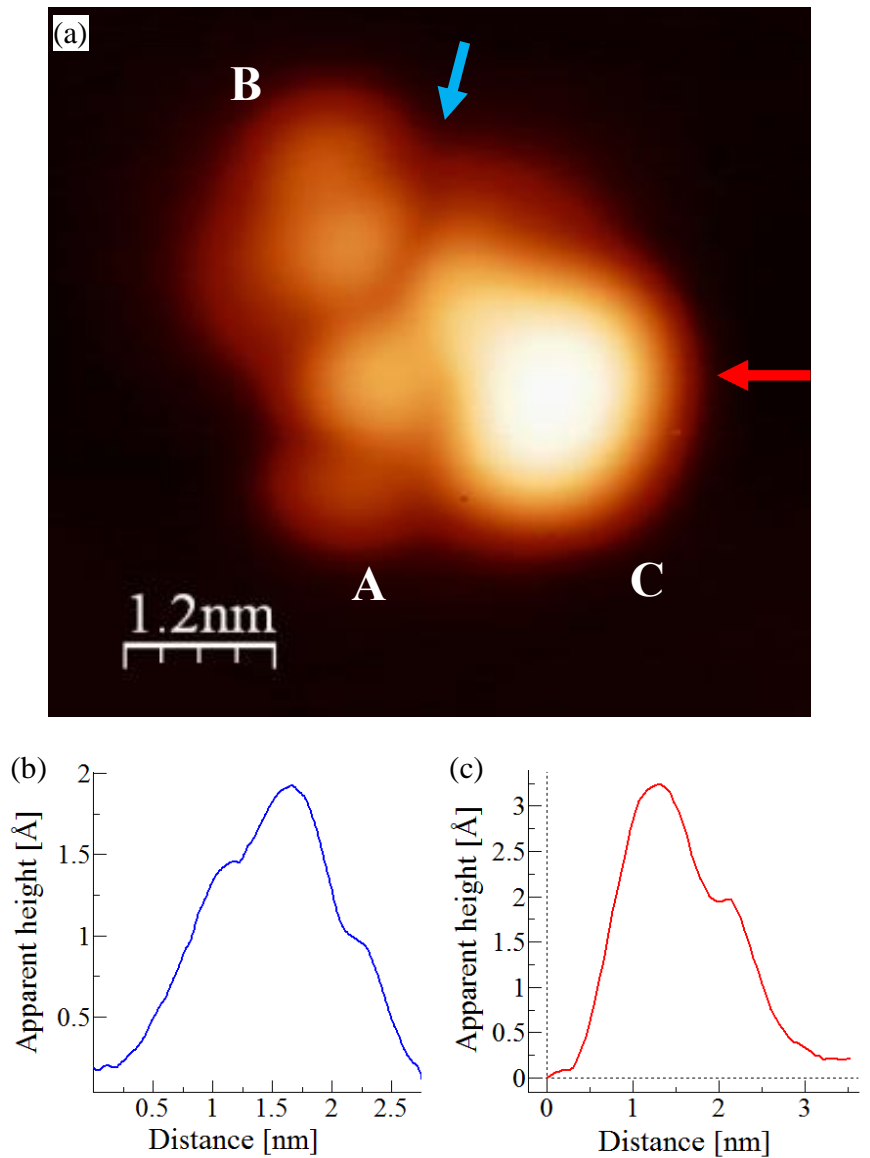

Figure 5. (a) STM image $\left(6 \times 6 \mathrm{~nm}^{2}\right)$ of a type (II) molecule (sample voltage $1.5 \mathrm{~V}$, tunneling current $2 \mathrm{pA}$ ). The blue and red arrows indicate the profile directions, respectively shown in (b) and (c). (b) Profile along molecule (II) showing an apparent height of the central and external lobes of part B of about $1.8 \AA$ and $0.8 \AA$ respectively. (c) Profile along molecule (II) showing an apparent height of part C above the $\operatorname{Ag}(111)$ of about $3 \AA$.

The image of type (II) objects presents a different structure. One of them is presented in Figure 5. The image reveals three features: two (numbered $\mathbf{A}$ and $\mathbf{B}$ in Fig. 5a) are rather similar with two small lobes and they appeared to be the image of the other by a rotational symmetry with an angle of $145^{\circ}$. The third feature $\mathbf{C}$ is the brightest and the largest protrusion of the image. It is composed by a single lobe with an angled shape of about $85^{\circ}$.

The geometry of this object should remind the molecular chemical structure of $\left[\mathrm{Ru}(\mathrm{dbm})_{2}(\mathrm{acac}-\mathrm{TIPSA})\right]$ : two symmetric parts corresponding to the two dbm ligands and the last one to the acac-TIPSA part of the molecule. For similar tunneling conditions, the corrugation of this object is smaller than in type (I). Indeed, for part $\mathbf{A}$ and $\mathbf{B}$, the central and external lobes, separated by $5 \AA$, exhibit an apparent height of about $1.8 \AA$ and $0.8 \AA$ respectively (Fig. 5b). Likewise, the apparent height of part $\mathbf{C}$ reaches $3.2 \AA$ (Fig. 5c). This part is $10 \AA$ away from the closest lobe of the part $\mathbf{A}$. Different tips were used to perform these images. Therefore, tips do not influence the observations and the experimental apparent heights are perfectly reproducible.

It should be noted that the shape of type (II) objects may change. Indeed, the part C may be oriented with respect to parts A and $\mathrm{B}$ either in an anticlockwise direction either in a clockwise direction as shown in Figure 6. 


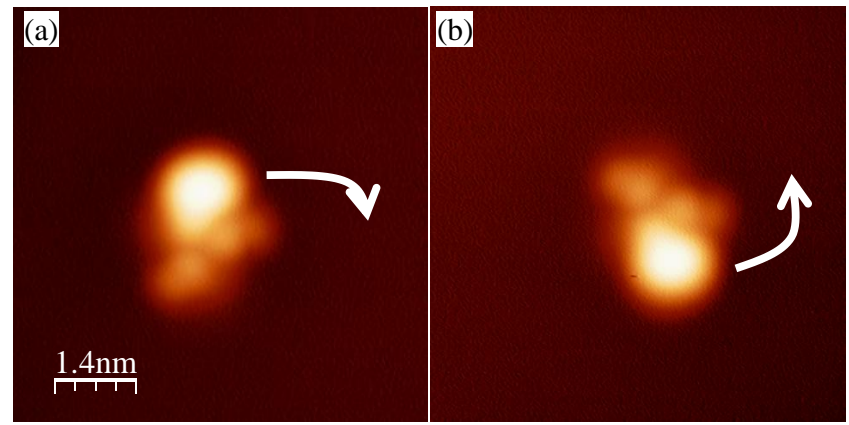

Figure 6. STM images $\left(7 \times 7 \mathrm{~nm}^{2}\right)$ of molecule (II) (sample voltage $-1.5 \mathrm{~V}$, tunneling current $2 \mathrm{pA}$ ). (a) In an anticlockwise orientation. (b) In a clockwise direction (arrows indicate the chiral orientation).

The global behaviour of the $[\mathrm{Ru}(\mathrm{dbm}) 2(\mathrm{acac}-\mathrm{TIPSA})]$ resembles that of the $\mathrm{Ru}(\mathrm{dbm})_{3}$, which is the first ruthenium complex studied of the series. ${ }^{43}$ Indeed, many similarities can be noticed. The objects of type (I) exhibit a higher corrugation on the STM image and are very stable on the surface. The second type of molecule presents a rather small apparent height and a chiral geometry. As we will see further, calculations support these specific adsorption geometries.

3.3. Adsorption and STM image calculation. Calculations have been performed to determine the adsorption state of the molecule. They have been carried out with an extended semi-empirical atom superposition and electron delocalization ${ }^{53}$ (ASED+) approach. ASED molecular orbital method is based on the extended Hückel molecular orbital theory and is a powerful numerical tool to describe the behaviour of large molecules ${ }^{54,55}$. Due to prohibitive computation consumption that such a system should require by using density functional theory (DFT), this semi-empirical method has been preferred. Moreover, ASED+ results have already shown very a good agreement with DFT results ${ }^{56}$. Standard parameters for carbon, silicon, hydrogen and oxygen were used. The $\left(\mathrm{H}_{\mathrm{ii}}, \zeta\right)$ extended Hückel parameters for $\mathrm{Ru}$ were chosen as $\mathrm{Ru} 5 \mathrm{~s}(-8.6,2.078), \mathrm{Ru} 5 \mathrm{p}(-3.28,2.043)$ and $\mathrm{Ru} 4 \mathrm{~d} \mathrm{H}_{\mathrm{ii}}=-11.12$ $\mathrm{eV}, \zeta_{1}=5.378$ and $\zeta_{2}=2.303$ with weighting coefficients of 0.534 and 0.6365 , respectively, taken from Hoffmann $e t$ al. ${ }^{57}$ On the other hand, these parameters have been successfully used for the ruthenium tris( $\beta$-diketonato) complexes previously studied. ${ }^{43}$ As for this complexe, two different structures were found after relaxation of the molecular geometry.

- In the first structure (Figure 7a,b), the two dbm groups are located almost parallel to the plane of the Ag(111) surface. Then, the molecular structure exhibits its TIPSA part perpendicular to the surface plane (Figure 7b).

- In the second relaxed structure (Figure 8a,b), the molecule is found to be with three phenyl groups on the surface exhibiting an octahedral geometry and with each oxygen atom above a hollow site on the $\mathrm{Ag}(111)$ surface.

The difference in energy between the two relaxed systems is $275 \mathrm{meV}$, comprising internal deformation of the adsorbed molecule $(95 \mathrm{meV})$ and the molecule/surface interaction $(180 \mathrm{meV})$. From Figure 8a, it appears clearly that the molecule shows a more distorted geometry due the flexibility of the benzene rings and the TIPSA moiety. It is worth to highlight that the central cage around the $\mathrm{Ru}$ atom is not distorted in the two types. The $\mathrm{Ru}$ atom keeps its coordination sphere intact (distance between $\mathrm{Ru}$ and $\mathrm{O}$ atoms is $2.09 \pm 0.02 \AA$ ) meaning that the interaction of the surface is weak enough to not influence the complex atom coordination. This is an important point if one considers that this complex $\mathbf{2}$ is part of a more elaborated molecule with several coordination centres. The adsorption will not preclude the magnetic coupling between these centres and one may anticipate a robust functionalized molecule upon adsorption.

Using these relaxed structures, the STM images of a $\left[\mathrm{Ru}(\mathrm{dbm})_{2}(\mathrm{acac}-\mathrm{TIPSA})\right]$ molecule were calculated with the elastic scattering quantum chemistry technique ${ }^{58}$ (ESQC) under the same tunnelling conditions as in the STM experiments. The calculated results displayed in Figure $7 \mathrm{c}$ and Figure $8 \mathrm{c}$ are consistent with the experimental results. Indeed, the standing structure presented in Figure 7c gives a single lobe in the calculated ESQC image and an apparent height of about $6 \AA$ in good agreement with the type (I). When the molecule is adsorbed with the three phenyl groups in contact with the Ag surface, all the TIPSA group is close to the surface and this leads to a less protruding structure as experimentally observed for the type (II) object. In this case, the distance between the brightest structures (about $1 \mathrm{~nm}$ in Figure 8c) is close to the one observed in Figure 5 (a) between the secondary lobe and the angled shape structure. 

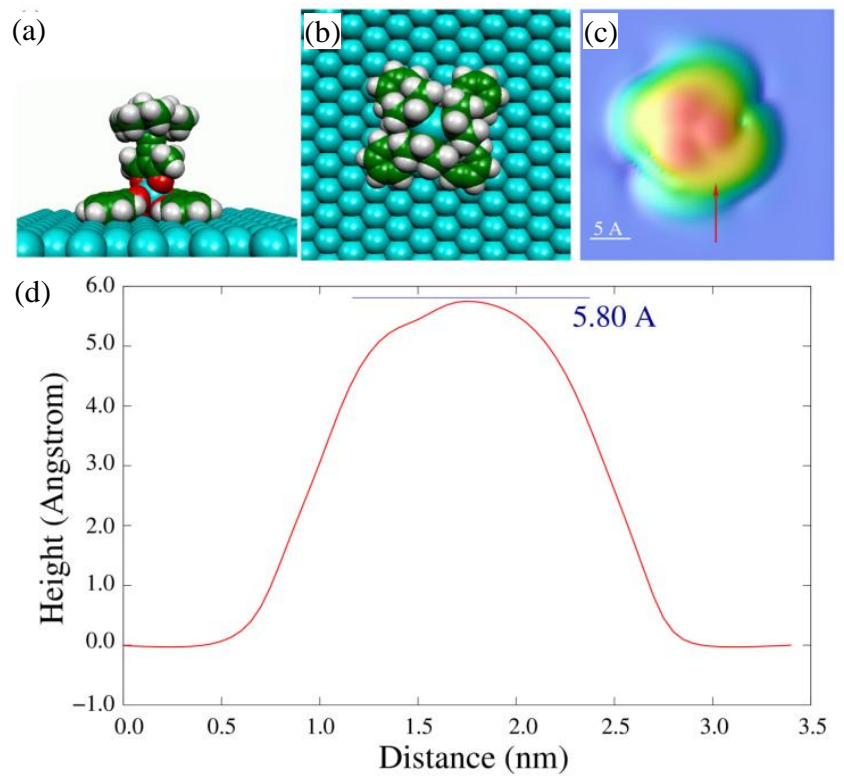

Figure 7. Space-filling models of [ $\mathrm{Ru}(\mathrm{dbm})_{2}$-acac-TIPSA] adsorbed on $\mathrm{Ag}(111)$ deduced from ASED+ calculations: (a) lateral view and (b) top view. (c) EHMO-ESQC calculated image of $\left[\mathrm{Ru}(\mathrm{dbm})_{2}\right.$-acac-TIPSA] adsorbed on $\mathrm{Ag}(111)$ under the same tunneling conditions as in the experimental STM. (d) Profile showing the calculated apparent height of the $\left[\mathrm{Ru}(\mathrm{dbm})_{2}\right.$-acac-TIPSA] molecule with respect to the $\operatorname{Ag}(111)$ surface as indicated by an arrow in (c).
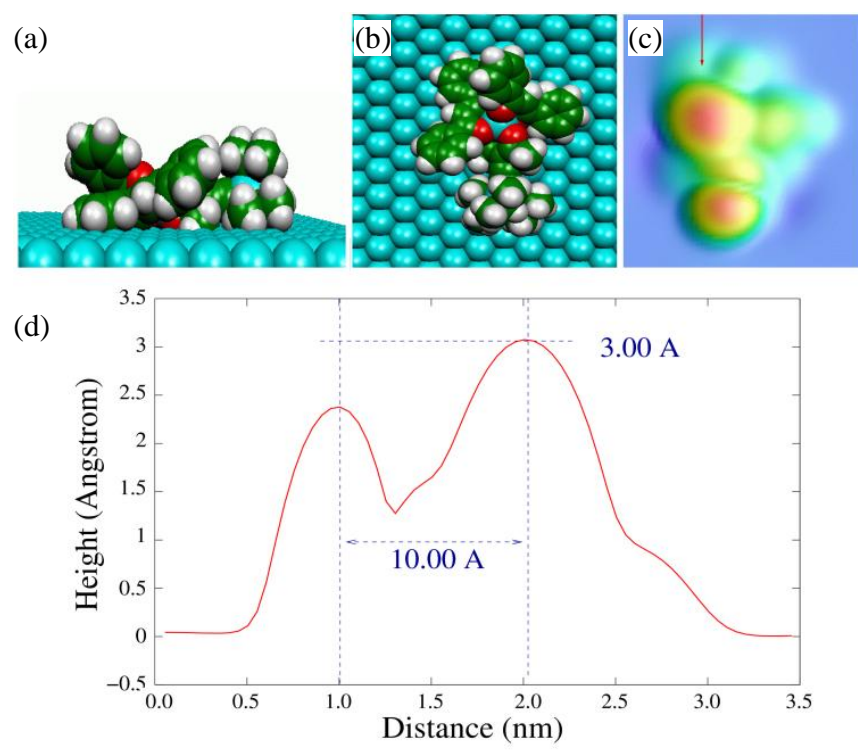

Figure 8. Space-filling models of [Ru(dbm) $)_{2}$ (acac-TIPSA)] adsorbed on $\operatorname{Ag}(111)$ : (a) lateral view and (b) top view. (c) EHMO-ESQC calculated image of $\left[\mathrm{Ru}(\mathrm{dbm})_{2}(\right.$ acac-TIPSA)] molecule adsorbed on $\operatorname{Ag}(111)$. (d) Profile showing the calculated apparent height ( $3 \AA$ ) of the molecule. The two bright protrusions are separated by about $10 \AA$.

These calculations therefore support the presence of the two adsorption geometries that lead to the two types of objects experimentally observed.

\section{CONCLUSION}

New magnetic Ru compounds have been synthesized and characterized using a set of complementary techniques such as electrochemistry and NMR spectroscopy. Single molecules have been observed by low temperature STM. These experiments 
suggest that this molecule can be deposited on a metallic surface without fragmentation. Experimental investigations and adsorption calculations unambiguously show that the interaction between this large complex and the metallic substrate induces two different geometries whose characteristics are very different from each other. After the previous experiments on $\left[\mathrm{Ru}\left(\mathrm{dbm}_{3}\right)\right], \mathrm{this}_{\mathrm{s}} \mathrm{new}$ complex is the second step towards the synthesis of a large Ru molecule including two metallic centers. The fact of being able to observe and to manipulate these large objects using a scanning tunneling microscope appears of fundamental importance for the future studies of the magnetic properties at the single molecular scale. In particular, the role played by the surface is only to support the molecule without perturbing its electronic and magnetic properties.

\section{AUTHOR INFORMATION}

Corresponding Author

* Fax: +33-5-62257999

E-Mail: jbonvoisin@cemes.fr

\section{ACKNOWLEDGMENT}

This work was in part supported by World Premier International Research Center (WPI) Initiative on Materials Nanoarchitectonics, MEXT, Japan and by the CNRS. YB and XB thank the ANR-COSINUS program through the SAMSON (System for Adaptive Modeling and Simulation Of Nano-objects) project. The images have been presented using the WSXM software. ${ }^{59}$

\section{SUPPORTING INFORMATION AVAILABLE}

Figure S1: Cyclic Voltammetry of 1 and $2\left(\mathrm{CH}_{2} \mathrm{Cl}_{2}, 0.1 \mathrm{M}\right.$ TBAH, 0.1 V.s-1); Figure S2: UV-Vis spectra of complexes 1 and 2 in $\mathrm{CH}_{2} \mathrm{Cl}_{2}$; Figure S3: ${ }^{1} \mathrm{H}$ NMR spectrum of complex 2 in $\mathrm{CD}_{2} \mathrm{Cl}_{2}$; Figure S4: ${ }^{13} \mathrm{C}$ NMR spectrum of complex 2 in $\mathrm{CD}_{2} \mathrm{Cl}_{2}$; Table S1: Table of crystallographic data for 2; Table S2: Table of selected bond lengths and bond angles for 2 . This material is available free of charge via the Internet at http://pubs.acs.org.

\section{REFERENCES}

(1) Song, H.; Reed, M. A.; Lee, T., Adv. Mater. 2011, 23, 1583-1608.

(2) Aromi, G.; Aguila, D.; Gamez, P.; Luis, F.; Roubeau, O., Chem. Soc. Rev. 2012, 41, 537-546.

(3) Lehmann, J.; Gaita-Arino, A.; Coronado, E.; Loss, D., Nature Nanotech. 2007, 2, 312-317.

(4) Lehmann, J.; Gaita-Arino, A.; Coronado, E.; Loss, D., J. Mater. Chem. 2009, 19, 1672-1677.

(5) Low, P. J., Dalton Transactions 2005, 2821-2824.

(6) Timco, G. A.; Carretta, S.; Troiani, F.; Tuna, F.; Pritchard, R. J.; Muryn, C. A.; McInnes, E. J. L.; Ghirri, A.; Candini, A.; Santini, P.; Amoretti, G.; Affronte, M.; Winpenny, R. E. P., Nature Nanotech. 2009, 4, 173-178.

(7) Sanvito, S., Chem. Soc. Rev. 2011, 40, 3336-3355.

(8) Petukhov, K.; Alam, M. S.; Rupp, H.; Stromsdorfer, S.; Muller, P.; Scheurer, A.; Saalfrank, R. W.; Kortus, J.; Postnikov, A.; Ruben, M.; Thompson, L. K.; Lehn, J. M., Coord. Chem. Rev. 2009, 253, 2387-2398.

(9) Wiesendanger, R., Rev. Mod. Phys. 2009, 81, 1495-1550.

(10) Bode, M., Rep. Prog. Phys. 2003, 66, 523-582.

(11) Neel, N.; Ferriani, P.; Ziegler, M.; Heinze, S.; Kroger, J.; Berndt, R., Phys. Rev. B 2012, 85, 155406.

(12) Hirjibehedin, C. F.; Lin, C. Y.; Otte, A. F.; Ternes, M.; Lutz, C. P.; Jones, B. A.; Heinrich, A. J., Science 2007, 317, 1199-1203.

(13) Hirjibehedin, C. F.; Lutz, C. P.; Heinrich, A. J., Science 2006, 312, 1021-1024.

(14) Ham, U.; Ho, W., Phys. Rev. Lett. 2012, 108, 106803.

(15) Tsukahara, N.; Noto, K. I.; Ohara, M.; Shiraki, S.; Takagi, N.; Takata, Y.; Miyawaki, J.; Taguchi, M.; Chainani, A.; Shin, S.; Kawai, M., Phys. Rev. Lett. 2009, 102, 167203.

(16) Heinze, S.; Bode, M.; Kubetzka, A.; Pietzsch, O.; X, N.; Blugel, S.; Wiesendanger, R., Science 2000, 288, 1805-1808. 
(17) Bode, M.; Heide, M.; von Bergmann, K.; Ferriani, P.; Heinze, S.; Bihlmayer, G.; Kubetzka, A.; Pietzsch, O.; Blugel, S.; Wiesendanger, R., Nature 2007, 447, 190-193.

(18) Gao, C. L.; Wulfhekel, W.; Kirschner, J., Phys. Rev. Lett. 2008, 101, 267205.

(19) Madhavan, V.; Chen, W.; Jamneala, T.; Crommie, M. F.; Wingreen, N. S., Science 1998, 280, 567569.

(20) Li, J. T.; Schneider, W. D.; Berndt, R.; Delley, B., Phys. Rev. Lett. 1998, 80, 2893-2896.

(21) Manoharan, H. C.; Lutz, C. P.; Eigler, D. M., Nature 2000, 403, 512-515.

(22) Kawahara, S. L.; Lagoute, J.; Repain, V.; Chacon, C.; Girard, Y.; Klein, J.; Rousset, S., Phys. Rev. B 2010, 82, 020406.

(23) Bork, J.; Zhang, Y. H.; Diekhoner, L.; Borda, L.; Simon, P.; Kroha, J.; Wahl, P.; Kern, K., Nature Phys. 2011, 7, 901-906.

(24) Iancu, V.; Deshpande, A.; Hla, S. W., Nano Lett. 2006, 6, 820-823.

(25) Mugarza, A.; Krull, C.; Robles, R.; Stepanow, S.; Ceballos, G.; Gambardella, P., Nat. Commun. 2011, 2, 490.

(26) Franke, K. J.; Schulze, G.; Pascual, J. I., Science 2011, 332, 940-944.

(27) Aynajian, P.; Neto, E. H. D.; Parker, C. V.; Huang, Y. K.; Pasupathy, A.; Mydosh, J.; Yazdani, A., Proc. Natl. Acad. Sci. USA 2010, 107, 10383-10388.

(28) Schmidt, A. R.; Hamidian, M. H.; Wahl, P.; Meier, F.; Balatsky, A. V.; Garrett, J. D.; Williams, T. J.; Luke, G. M.; Davis, J. C., Nature 2010, 465, 570-576.

(29) Tsukahara, N.; Shiraki, S.; Itou, S.; Ohta, N.; Takagi, N.; Kawai, M., Phys. Rev. Lett. 2011, 106, 187201.

(30) Heinrich, A. J.; Gupta, J. A.; Lutz, C. P.; Eigler, D. M., Science 2004, 306, 466-469.

(31) Loth, S.; Etzkorn, M.; Lutz, C. P.; Eigler, D. M.; Heinrich, A. J., Science 2010, 329, 1628-1630.

(32) Loth, S.; Baumann, S.; Lutz, C. P.; Eigler, D. M.; Heinrich, A. J., Science 2012, 335, 196-199.

(33) Grill, L., J. Phys.: Condens. Matter 2010, 22, 084023.

(34) Yu, M.; Xu, W.; Benjalal, Y.; Barattin, R.; Laegsgaard, E.; Stensgaard, I.; Hliwa, M.; Bouju, X.; Gourdon, A.; Joachim, C.; Linderoth, T. R.; Besenbacher, F., Nano Research 2009, 2, 254-259.

(35) Zambelli, T.; Goudeau, S.; Lagoute, J.; Gourdon, A.; Bouju, X.; Gauthier, S., Chemphyschem 2006, 7, 1917-1920.

(36) Cho, J.; Berbil-Bautista, L.; Pechenezhskiy, I. V.; Levy, N.; Meier, S. K.; Srinivasan, V.; Kanai, Y.; Grossman, J. C.; Vollhardt, K. P. C.; Crommie, M. F., Acs Nano 2011, 5, 3701-3706.

(37) Guo, S.; Kandel, S. A., J. Phys. Chem. Lett. 2010, 1, 420-424.

(38) Liu, K.; Wang, X. H.; Wang, F. S., Acs Nano 2008, 2, 2315-2323.

(39) Lu, Y. H.; Quardokus, R.; Lent, C. S.; Justaud, F.; Lapinte, C.; Kandel, S. A., J. Am. Chem. Soc. 2010, 132, 13519-13524.

(40) Ng, Z. Y.; Loh, K. P.; Li, L. Q.; Ho, P.; Bai, P.; Yip, J. H. K., Acs Nano 2009, 3, 2103-2114.

(41) Seo, K.; Konchenko, A. V.; Lee, J.; Bang, G. S.; Lee, H., J. Am. Chem. Soc. 2008, 130, 2553-2559.

(42) Guo, S.; Kandel, S. A., J. Chem. Phys. 2008, 128, 014702.

(43) Munery, S.; Ratel-Ramond, N.; Benjalal, Y.; Vernisse, L.; Guillermet, O.; Bouju, X.; Coratger, R.; Bonvoisin, J., Eur. J. Inorg. Chem. 2011, 2698-2705.

(44) Duisenberg, A. J. M. Reflections on Area Detectors. Utrecht University, The Netherlands, Utrecht, 1998.

(45) Burla, M. C.; Caliandro, R.; Camalli, M.; Carrozzini, B.; Cascarano, G. L.; de Caro, L.; Giacovazzo, C.; Polidori, G.; Spagna, R., J. Appl. Cryst. 2005, 38, 381-388.

(46) Farrugia, L. J., J. Appl. Cryst. 1999, 32, 837-838.

(47) Sheldrick, G. M., Acta Cryst. 2008, A64, 112-122.

(48) Bruker. SADABS Bruker AXS Inc. Madison, Wisconsin, USA, 2001.

(49) Sheldrick, G. M. SADABS. University of Göttingen, Germany, 1996. 
(50) Kasahara, Y.; Hoshino, Y.; Kajitani, M.; Shimizu, K.; Sato, G. P., Organometallics 1992, 11, 196871.

(51) Munery, S.; Jaud, J.; Bonvoisin, J., Inorg. Chem. Comm. 2008, 11, 975-977.

(52) Wang, P.; Miller, J. E.; Henling, L. M.; Stern, C. L.; Frank, N. L.; Eckermann, A. L.; Meade, T. J., Inorg. Chem. 2007, 46, 9853-9862.

(53) Ample, F.; Joachim, C., Surf. Sci. 2006, 600, 3243.

(54) Bosson, M.; Richard, C.; Plet, A.; Grudinin, S.; Redon, S., J. Comput. Chem. 2012, 33, 779-790.

(55) Makoudi, Y.; Duverger, E.; Arab, M.; Cherioux, F.; Ample, F.; Rapenne, G.; Bouju, X.; Palmino, F., Chemphyschem 2008, 9, 1437-1441.

(56) Ample, F.; Joachim, C., Surf. Sci. 2008, 602, 1563-1571.

(57) Jorgensen, K. A.; Hoffmann, R., J. Am. Chem. Soc. 1986, 108, 1867-1876.

(58) Sautet, P.; Joachim, C., Phys. Rev. B. 1988, 38, 12238.

(59) Horcas, I.; Fernandez, R.; Gomez-Rodriguez, J. M.; Colchero, J.; Gomez-Herrero, J.; Baro, A. M., Rev. Sci. Instrum. 2007, 78, 013705.

Table of Contents Image

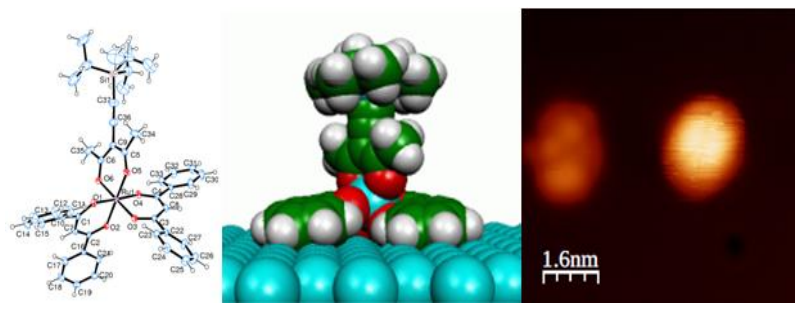

